Available online on 15.11.2020 at http://jddtonline.info
Open Access to Pharmaceutical and Medical Research
unrestricted non-commercial use, provided the original work is properly cited

Open $\odot$ Access

Research Article

\title{
Immunomodulatory Effect of Sodium Saccharin and Potassium Acesulfame in BALB/C Mice in Short-Term Trials
}

\author{
Remil Asma*, Benali Mohammed \\ Laboratory of Biotoxicology, Department of Biology, Faculty of Sciences of Nature and Life, Djilali Liabès University, 22000, Sidi Bel Abbes, \\ Algeria
}

\begin{abstract}
Introduction: Sweeteners are molecules that give a sweet taste to a foodstuff. The question of the correct use of sweeteners is still being studied because the results of investigations are often contradictory.

Objective: the current study aims at evaluating the risk of short-term immunotoxicity induced by sodium saccharin and potassium acesulfame in $\mathrm{BALB} / \mathrm{c}$ mice.

Methods: Animals are given low concentrations of sweeteners $(0 \%, 0.5 \%, 1 \%, 2 \%)$ in drinking water for 90 days. During this period, a subcutaneous immunization is conducted. Blood is taken from the retro-orbital sinus and the animals are sacrificed by cervical dislocation. Weight measurements and histological studies have involved spleen, thymus, bladder and lungs. Levels of immunoglobulins are measured by reversed single radial immunodiffusion.

Results: A significant rise in the consumption of sweeteners is found in the groups receiving doses of $1 \%$ and $2 \%(\mathrm{p}<0.05)$. Organ weight is not affected in both sexes $(p>0.05)$. Histology shows no tissue abnormality of thymus and lungs in groups consuming sweeteners. However, histological disturbances of the spleen are observed in mice that have received the dose of $2 \%$. Histological study of bladder has revealed hyperplasia in the groups receiving $1 \%$ and $2 \%$ of sweeteners. Immunodiffusion assay shows no change in immunoglobulin levels in the groups consuming sweeteners $(\mathrm{p}>0.05)$.
\end{abstract}

Conclusion: Sweeteners have adverse effects on the immune system in BALB/c mice and induce histological abnormalities in the spleen and bladder.

Keywords: Sweeteners, Saccharin, Potassium Acesulfame, Immunotoxicity, Immunoglobulins, Reversed single Radial Immunodiffusion.

Article Info: Received 24 Aug 2020; $\quad$ Review Completed 11 Oct 2020; $\quad$ Accepted 18 Oct 2020; $\quad$ Available online 15 Nov 2020

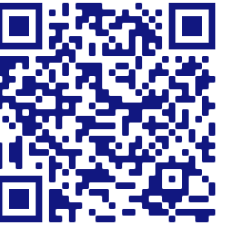

Abbes, Algeria

Cite this article as:

Remil A, Benali M, Immunomodulatory Effect of Sodium Saccharin and Potassium Acesulfame in BALB/C Mice in ShortTerm Trials, Journal of Drug Delivery and Therapeutics. 2020; 10(6):1-10 http://dx.doi.org/10.22270/jddt.v10i6.4534

*Address for Correspondence:

REMIL Asma, Department of Biology, Faculty of Sciences of Nature and Life, Djilali Liabès University, 22000, Sidi Bel

\section{INTRODUCTION}

Artificial sweeteners are molecules that have sweetening power and are able to give the sweet flavor. These substances are used during the last World War when sugar was lacking. Sweeteners have a great role in human nutrition because of their effects on glycemic regulation. They help to limit sugar intake in overweight or obese people. They also can replace sugar in diabetics ${ }^{1}$.

Sodium saccharin and potassium acesulfame are the main intense sweeteners that do not provide calories. Sodium saccharin has a sweetening power 300 to 400 stronger than that of sucrose 2 . Potassium acesulfame is about 200 times as sweet as sucrose 3. These sweeteners are authorized in Algeria by the Algerian directive in 1999 and are used as tabletop sweeteners for the manufacture of foodstuffs 4 .

Since the beginning of their use, sweeteners have been linked to the appearance of many effects in humans, saccharin has been suspected carcinogenic 5. Many data have shown the toxicity of sodium saccharin ${ }^{5-9}$, and potassium acesulfame ${ }^{10}$ 11; but few data have been performed on the immunotoxicity of these two sweeteners 12-14.

The main objective of this work is to evaluate the immunotoxic risk induced by short-term exposure to saccharin and acesulfame in BALB/c mice. 
We will study the immunotoxicity parameters (immunosuppression or immunostimulation) involving changes and histology in secondary immune organs (rate and thymus) and other target organs (bladder and lungs). Also, we will evaluate the level of gamma immunoglobulins (IgG) by optimization of the reversed single radial immunodiffusion.

\section{MATERIAL AND METHODS}

\section{Sweeteners Consumption}

Male and female BALB/c mice aged between 5 to 9 weeks, are divided into four groups putting six mice in each cage (n = 6) 15-16. They have received standard diets and drinking water based on sodium saccharin and potassium acesulfame (an equal mixture) for three months to induce subchronic immunotoxicity 15. Sweetener concentrations are in the order of $0.5 \%, 1 \%$ and $2 \%$ respectively for the first, second and third groups with a control group 12-13.

\section{Immunization of Animals}

Immunization phase includes primary immunization and booster one. We have mixed an equal volume of Freund's complete adjuvant (ACF) (Sigma F5881, lot 093K832) with the antigen solution (bovine casein) (Merck, art. 2244) ${ }^{17}$. Then, we have taken $1 \mathrm{ml}$ of the ACF and $1 \mathrm{ml}$ of the antigen solution containing $25 \mu \mathrm{g}$ of the antigen and emulsified both using the vortex. Afterwards, we injected $100 \mu \mathrm{l}$ of this mixture into five sites along the back of each mouse. After 14 days and 44 days, we repeated the booster injections but the emulsion was done this time with incomplete Freund's adjuvant (AIF) (F5506, lot 025K810) 18-20.

\section{Blood Collection}

Ten days after each immunization, we collected $1 \mathrm{ml}$ of blood from the retro-orbital sinus of BALB/c mice. The collected blood is transferred to an Eppendorf tube and centrifuged at $2500 \mathrm{~g}$ at $4{ }^{\circ} \mathrm{C}$ for $15 \mathrm{~min}$. The blood was aliquoted and frozen at $\left(-20^{\circ} \mathrm{C}\right)$ until use 21 .

\section{Organ Harvesting}

The animals were sacrificed by cervical dislocation 22 , and are rapidly dissected. The organs removed are the spleen and the bladder that are located in the abdominal cavity, the thymus and the lungs are located in the thoracic cavity. These organs are weighed for the determination of their relative and absolute weights. Thus, they were fixed in $10 \%$ buffered formalin and stored at room temperature until use 23.

\section{Histological Study}

\section{Sample Processing}

After fixation in $10 \%$ buffered formalin, the tissues are dehydrated in 3 successive baths of acetone in an oven at 40 ${ }^{\circ} \mathrm{C}$. Each bath lasts 45 minutes. Later, the pieces are clarified by placing them in two xylene baths in an oven and at $40{ }^{\circ} \mathrm{C}$ for 30 minutes in the general case ${ }^{24}$. Then, the samples are placed in three successive paraffin baths each at a temperature of $56{ }^{\circ} \mathrm{C}$ for $60 \mathrm{~min}$ for the bladder and $90 \mathrm{~min}$ for the lungs, spleen and thymus ${ }^{24}$. The samples are placed in a metal molds and embedded in paraffin, the plastic cassettes are attached and the volume is completed with paraffin. Then, they have been frozen for $15 \mathrm{~min}$ for good solidification. The blocks obtained containing the fragments of organs are cut with the microtome at a thickness of $7 \mu \mathrm{m}$. The sections are placed on glass slides washed previousely with soapy water, rinsed, dried on absorbent paper and covered with adhesive liquid (glycerinated albumin). The slides are dewaxed by placing them in two successive baths of toluene. Each bath lasts $10 \mathrm{~min}$. Then, they are rehydrated by placing them in two successive baths of ethanol of decreasing degrees $\left(100^{\circ}, 95^{\circ}, 90^{\circ}, 70^{\circ}\right)$ respectively. Each bath lasts 2 min. The last bath is followed by rinsing with running water for 5 minutes 23 .

\section{Staining and Microscopic Observation}

Staining of the histological slides was done with haemaluneosin for $03 \mathrm{~min}$ and $30 \mathrm{sec}$. The slides are washed with plain water until the color changes to blue-black, and then dipped in eosin (1\%) for $2 \mathrm{~min}$. They are put in two successive baths of ethanol at $70^{\circ}$ then at $96^{\circ}$ for 5 min each to relieve overcoloring. Finally, they are placed in xylene twice for $5 \mathrm{~min}$. The preparations are mounted by applying the slides immediately against a coverslip containing a drop of Canada balsam which serves to stick it to the slide. The prepared slides are allowed to dry and then examined under a microscope ${ }^{24}$.

\section{Evaluation of Immunoglobulins by Reversed Single Radial Immunodiffusion}

The preparation of the antigen solution is done by diluting $0.1 \mathrm{~g}$ of bovine casein in $100 \mathrm{ml}$ in sodium acetate buffer $\mathrm{pH}$ 7.2 . We mixed $6 \mathrm{ml}$ of the antigen solution $(0.75 \mathrm{mg} / \mathrm{ml})$ with an equal volume $(6 \mathrm{ml})$ of agar prepared previously from lyophilized agar in a water bath at $100^{\circ} \mathrm{C}$. In sterile Petri dishes and at temperature of $50^{\circ} \mathrm{C}$, we poured a volume of 12 $\mathrm{ml}$ of the mixture (antigen solution + agar) and allowed to dry in the open air. These boxes can be stored at $4^{\circ} \mathrm{C}$. After solidification of the mixture, we perforated the gel to obtain wells of $3 \mathrm{~mm}$ diameter. In each we deposited undiluted antiserum. The dishes are incubated for three days at a temperature of $37^{\circ} \mathrm{C}$ in paraffin oil to prevent the desiccation of gel $25-27$.

\section{Data Analysis}

The results are expressed as means and standard errors

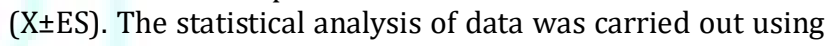
Statview version 5.0. The statistical data analysis of different groups is carried out by the Student t-test; this parametric statistical test was adapted for a comparative analysis between the means of the experimental groups and that of the control group. In all cases, a value of $p<0.05$ was considered significant.

\section{RESULTS}

\section{Sweeteners Consumption}

The difference between the averages of the four groups is highly significant $(\mathrm{p}<0.0001)$. The mice receiving drinking water supplemented with saccharin and acesulfame $\mathrm{K}$ consumed more than those subjected to the control diet (figure 1,2). Thus, a significantly small difference is observed in the mice that consumed the dose of $0.5 \%$ compared to those receiving $1 \%$ and $2 \%$ of sweeteners. 


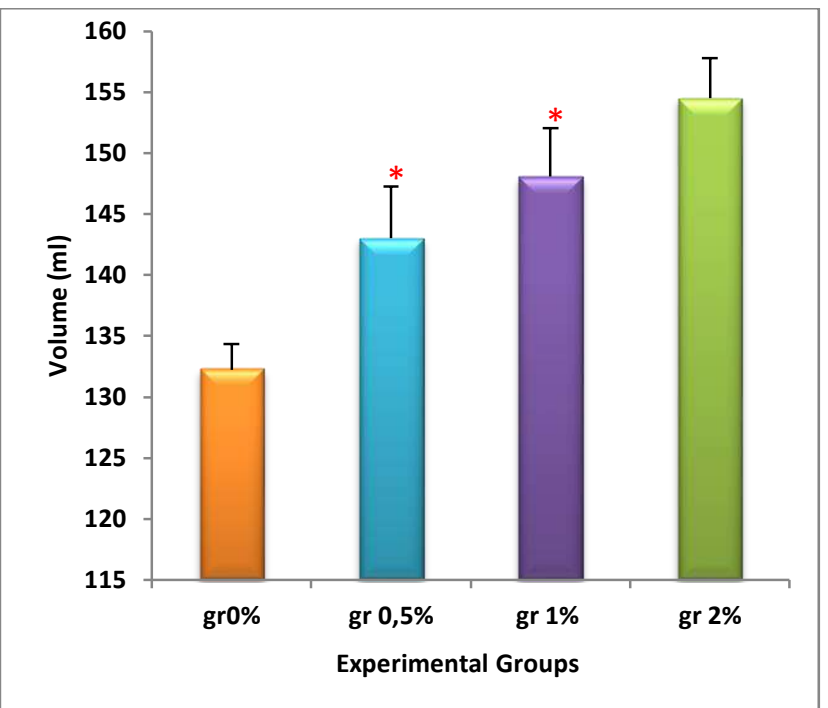

Figure 1: Sweeteners consumption by the BALB/c males. Data is expressed as the mean \pm standard error of the mean of two replicates $(n=6)$. An asterisk $(*)$ indicates the statistical difference to the control group $(\mathrm{P}<0.05)$. gr0\%: group receives drinking water with $0 \%$ sweeteners (control group). gr0, $5 \%$ : group receives $0,5 \%$ of sweeteners in drinking water. gr $1 \%$ : group receives $1 \%$ of sweeteners in drinking water. gr $2 \%$ : group receives $2 \%$ in drinking water.

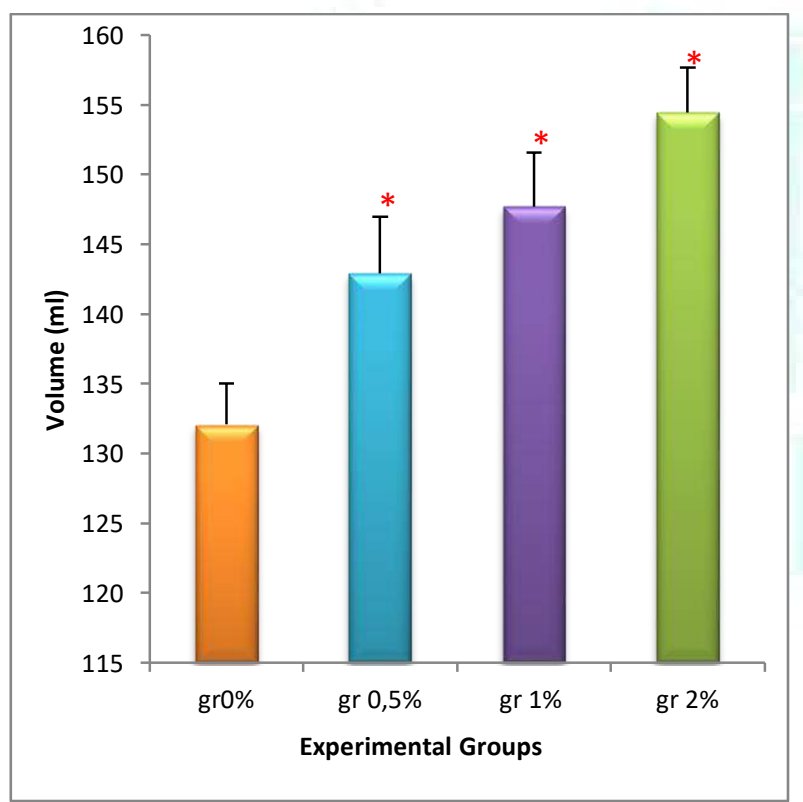

Figure 2: Sweeteners consumption by the BALB/c females. Data is expressed as the mean \pm standard error of the mean of two replicates $(\mathrm{n}=6)$. An asterisk $\left({ }^{*}\right)$ indicates the statistical difference to the control group $(\mathrm{P}<0.05)$. gr0\%: group receives drinking water with $0 \%$ sweeteners (control group). gr $0,5 \%$ : group receives $0,5 \%$ of sweeteners in drinking water. gr $1 \%$ : group receives $1 \%$ of sweeteners in drinking water. gr $2 \%$ : group receives $2 \%$ in drinking water.

\section{Body Weight Changes}

The weekly weight monitoring of BALB/c mice is represented in figures 3 and 4 . The results show that all the animals present an increase in weight over time, but the statistical analysis did not show significant difference compared with control values ( $p>0.05$ ).

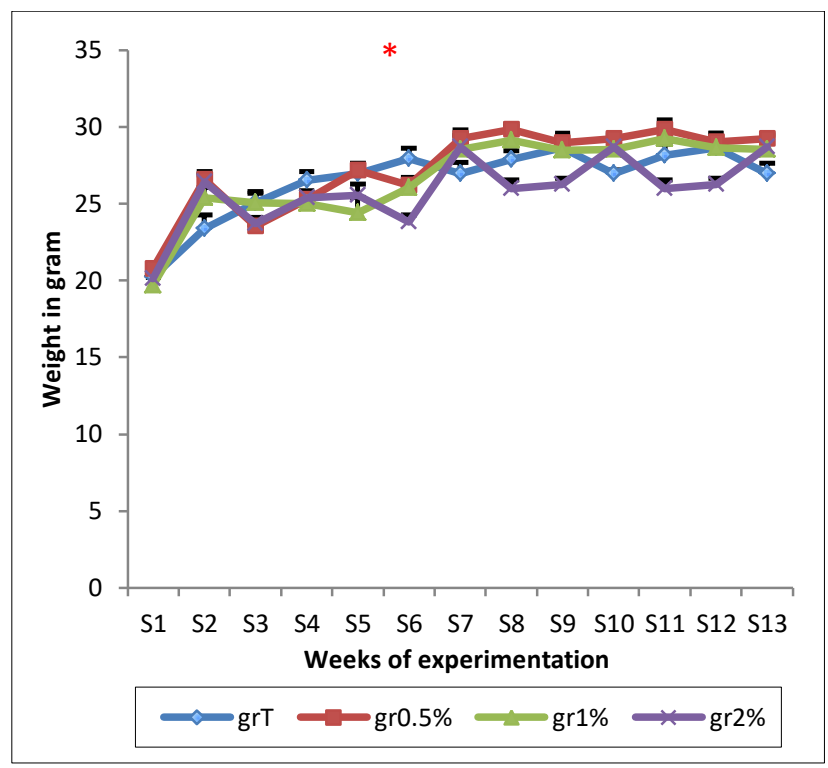

Figure 3: Weight evolution of male mice subjected to the experiment. Data is expressed as the mean \pm standard error of the mean of two replicates $(n=6)$. grT: group receives drinking water with $0 \%$ sweeteners (control group). gr $0,5 \%$ : group receives $0,5 \%$ of sweeteners in drinking water. gr $1 \%$ : group receives $1 \%$ of sweeteners in drinking water. gr $2 \%$ : group receives $2 \%$ in drinking water. S: Week.

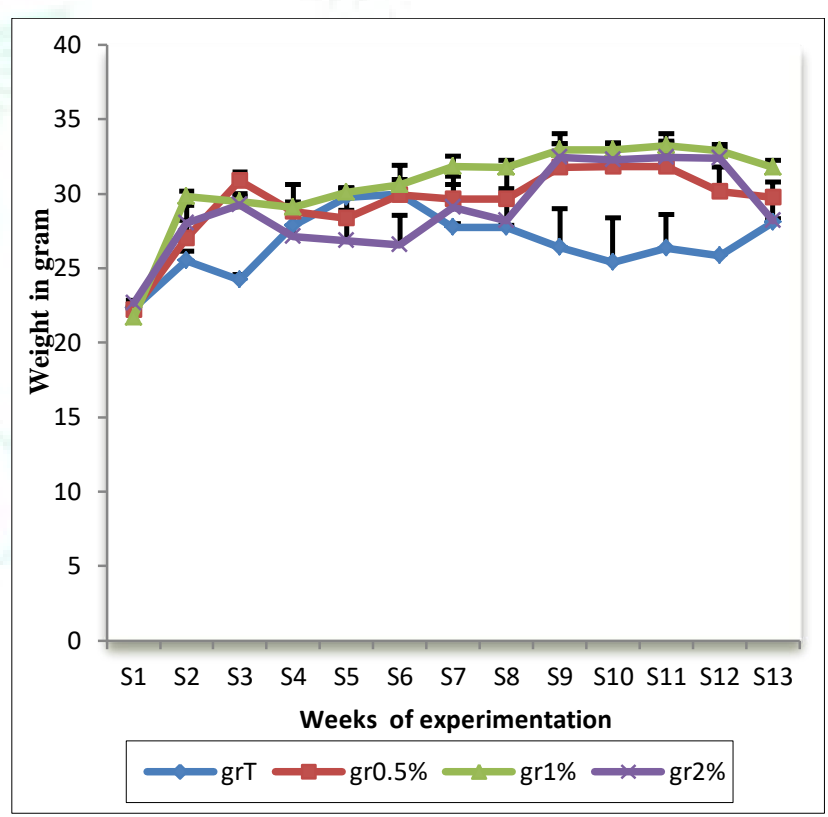

Figure 4: Weight evolution of female mice subjected to the experiment. Data is expressed as the mean \pm standard error of the mean of two replicates $(n=6)$. grT: group receives drinking water with $0 \%$ sweeteners (control group). gr $0,5 \%$ : group receives $0,5 \%$ of sweeteners in drinking water. gr $1 \%$ : group receives $1 \%$ of sweeteners in drinking water. gr $2 \%$ : group receives $2 \%$ in drinking water. S: Week.

\section{Organ Weights}

Whatever the amount of sweeteners consumed, the average organ weights (spleen, thymus, lungs, and bladder) are higher than those of the control group (Table 1). The Student's test indicates that there is no significant difference between the groups consuming the sweeteners and the control mice regardless the dose of ingested sweeteners $(p>0.05)$. 
Table 1: Organ weights in milligrams (mg) of mice subjected to the experiment. Data is expressed as the mean \pm standard error of the mean of two replicates $(n=6) . \delta^{\lambda}$ : males, $q$ : females.

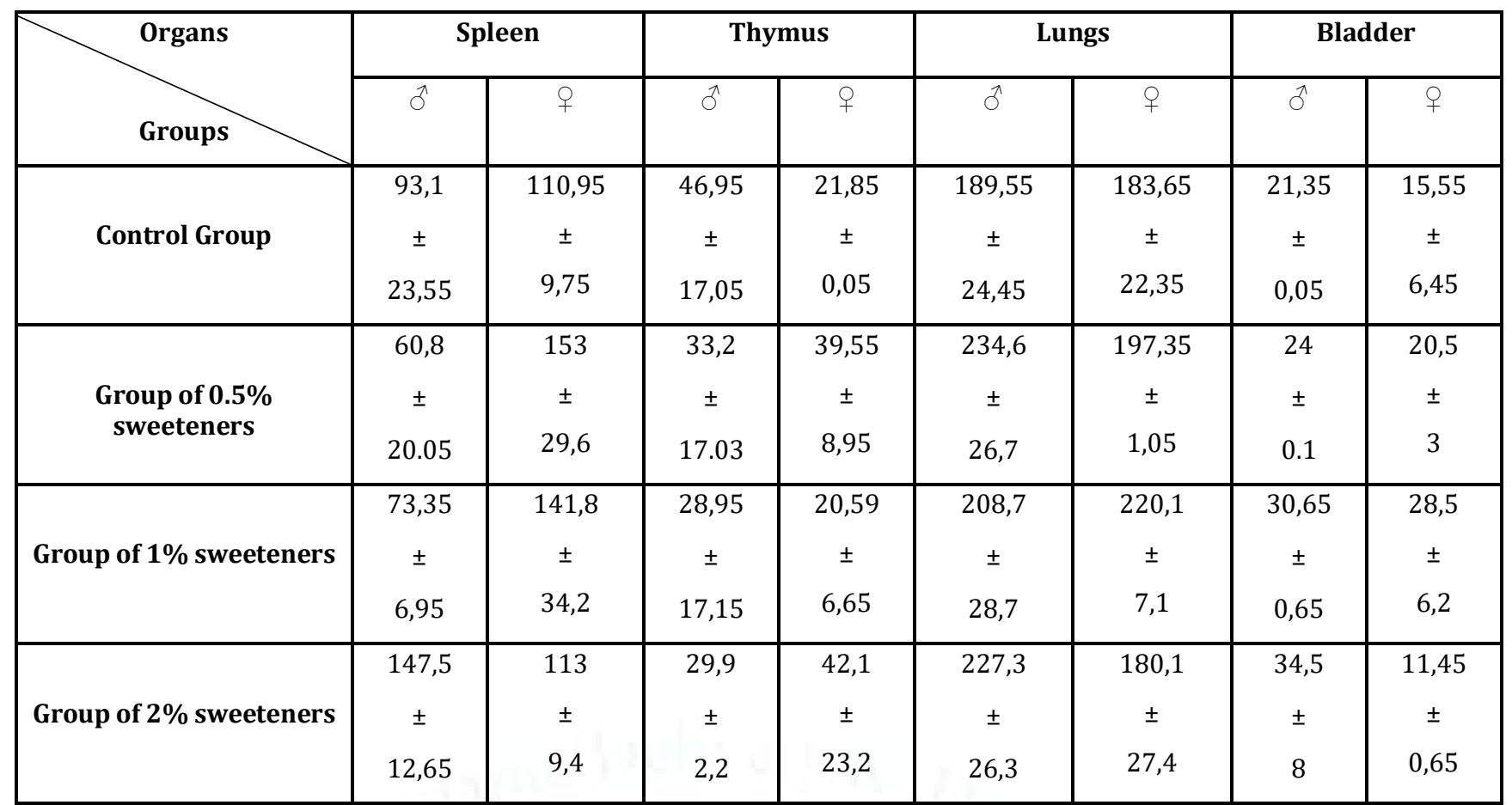

\section{Histology of Organs}

\section{Spleen}

Figures 5, 6 show respectively the histological sections in males and females. In both sexes, microscopic examination at low magnification (40x) shows an abundance of germinal lymphatic cells in the control group (figure 5a, 6a) and the group of females receiving $0.5 \%$ of sweeteners (figure $6 \mathrm{~b}$ ) compared to other groups. We noted a decrease in the number of macrophages and polymorphonuclear cells in groups of $1 \%$ and $2 \%$ (figure $5 c, 5 d, 6 c, 6 d$ ). In the group receiving $2 \%$ sweeteners, the follicular cells of the spleen appear voluminous and atypical in comparison with those in the control group (figure $5 \mathrm{~d}, 6 \mathrm{~d}$ ).
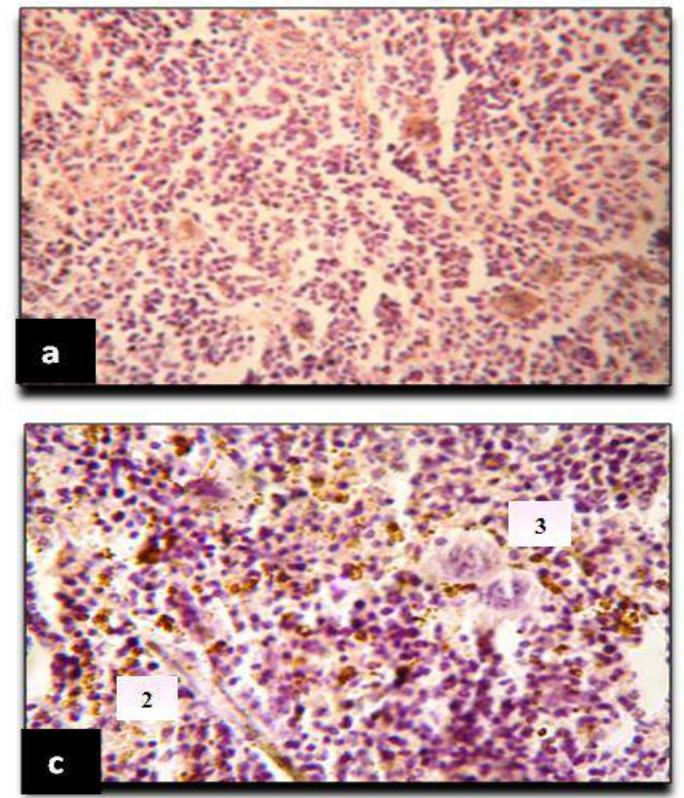
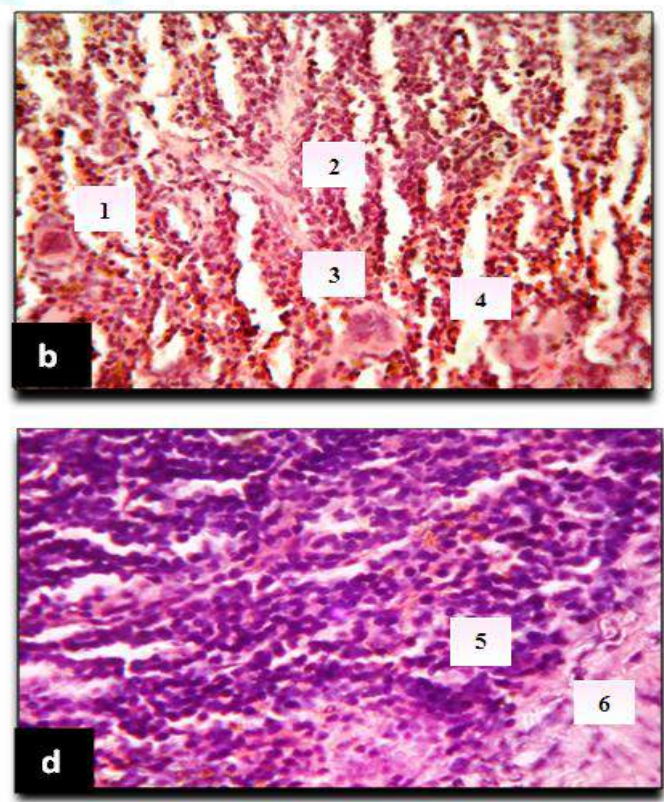

Figure 5: Histological sections of the spleen of male BALB/c mice (400X). a: control group, b: group of $0.5 \%$ sweeteners, c: group of $1 \%$ sweeteners, d: group of $2 \%$ sweeteners. b1: Macrophage; b2, c2: follicular arteriole; b3, c3: megakaryocyte; b4: polynuclear cell; b5: white pulp; b6: red pulp; d7: lymphocytic cap. 

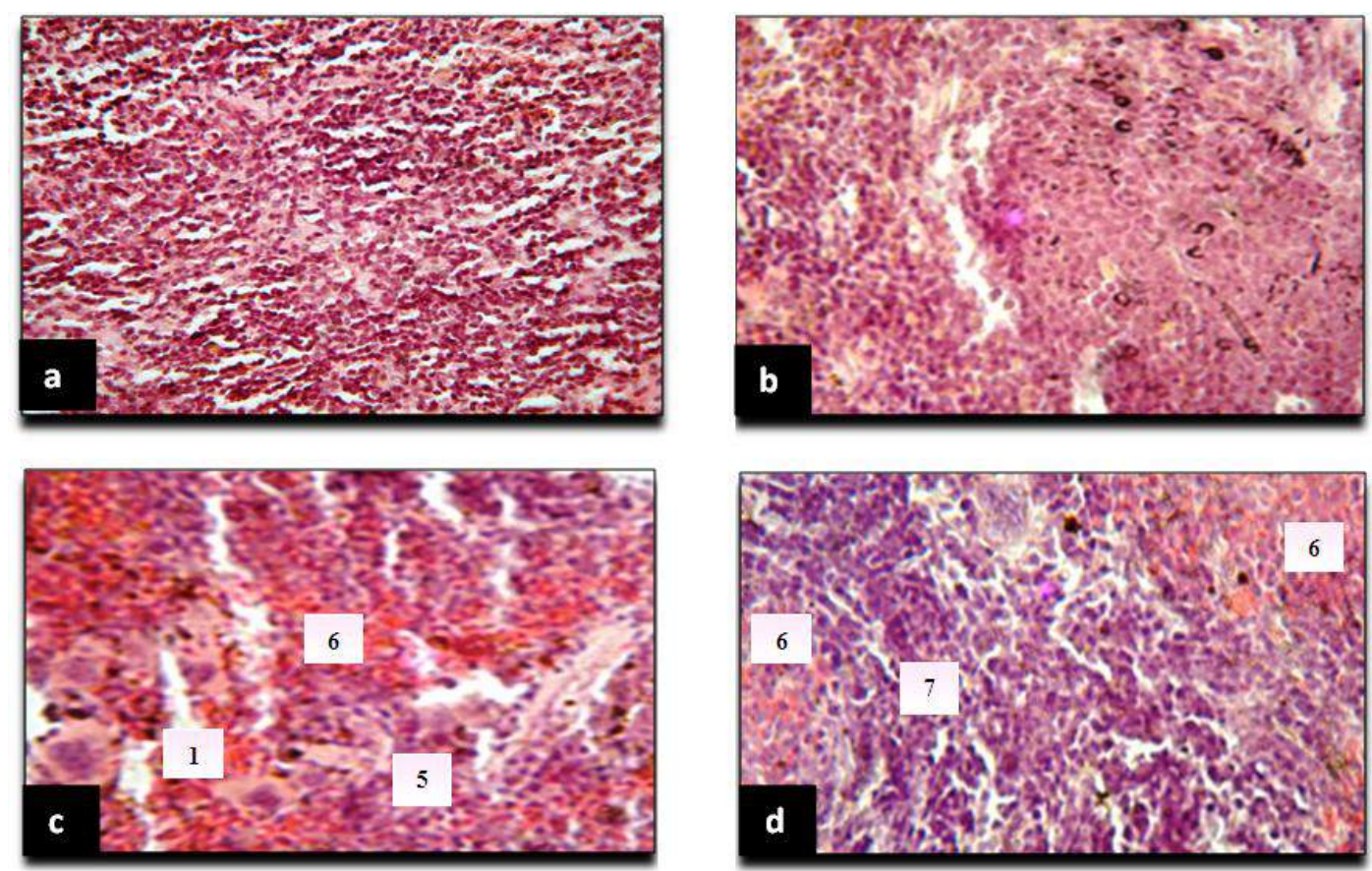

Figure 6: Histological sections of the spleen of female BALB/c mice (400X). a: control group, b: group of 0.5\% sweeteners, c: group of $1 \%$ sweeteners, d: group of $2 \%$ sweeteners. b1: Macrophage; b2, c2: follicular arteriole; b3, c3: megakaryocyte; b4: polynuclear cell; b5: white pulp; b6: red pulp; d7: lymphocytic cap.

\section{Thymus}

Whatever the sex, all groups, which received sweeteners, did not have any tissue abnormalities when compared to the control group. We noticed that an abundance of thymocytes in all groups of animals studied and the thymic lobules have a regular structure (figure $7 \mathrm{a}, \mathrm{c}$ ).
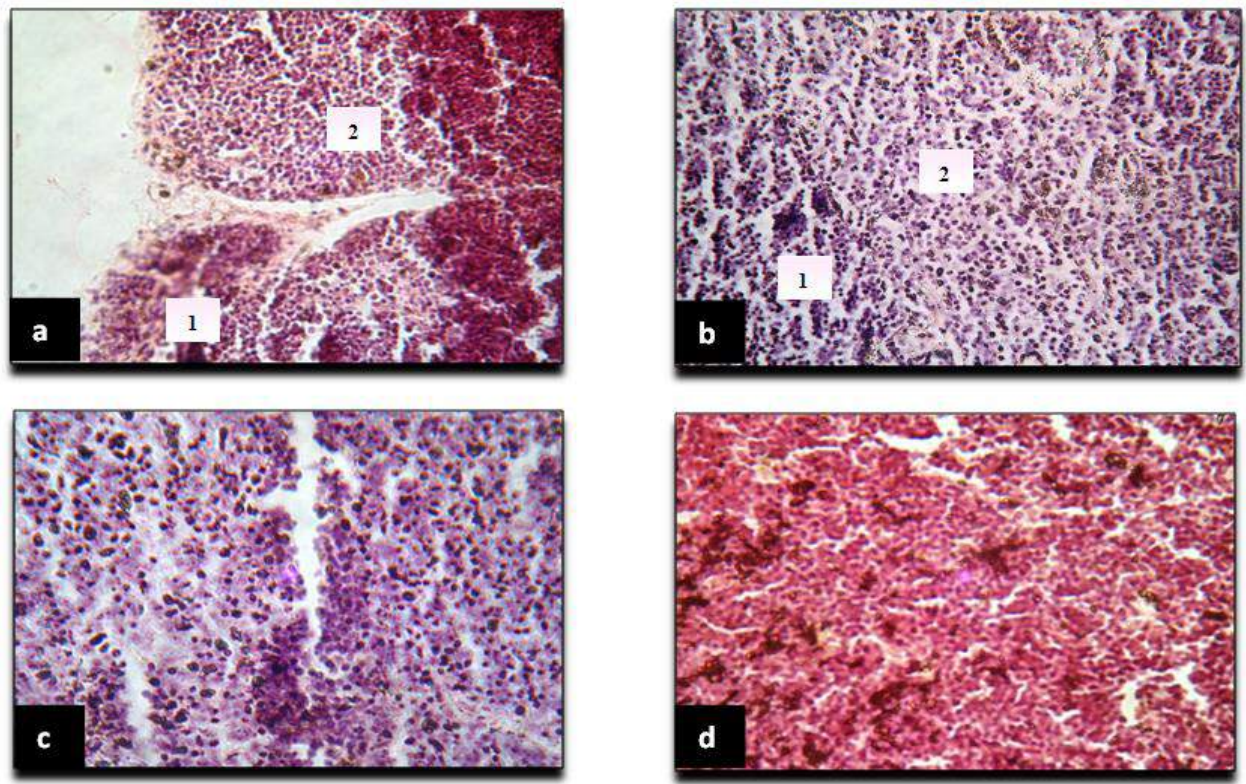

Figure 7: Histological sections of the thymus of male BALB/c mice (400X). a: control group, b: group of 0.5\% sweeteners, c: group of $1 \%$ sweeteners, d: group of $2 \%$ sweeteners. a1, b1: cortical zone; a2, b2: spinal zone; c3: thymic lobules. 

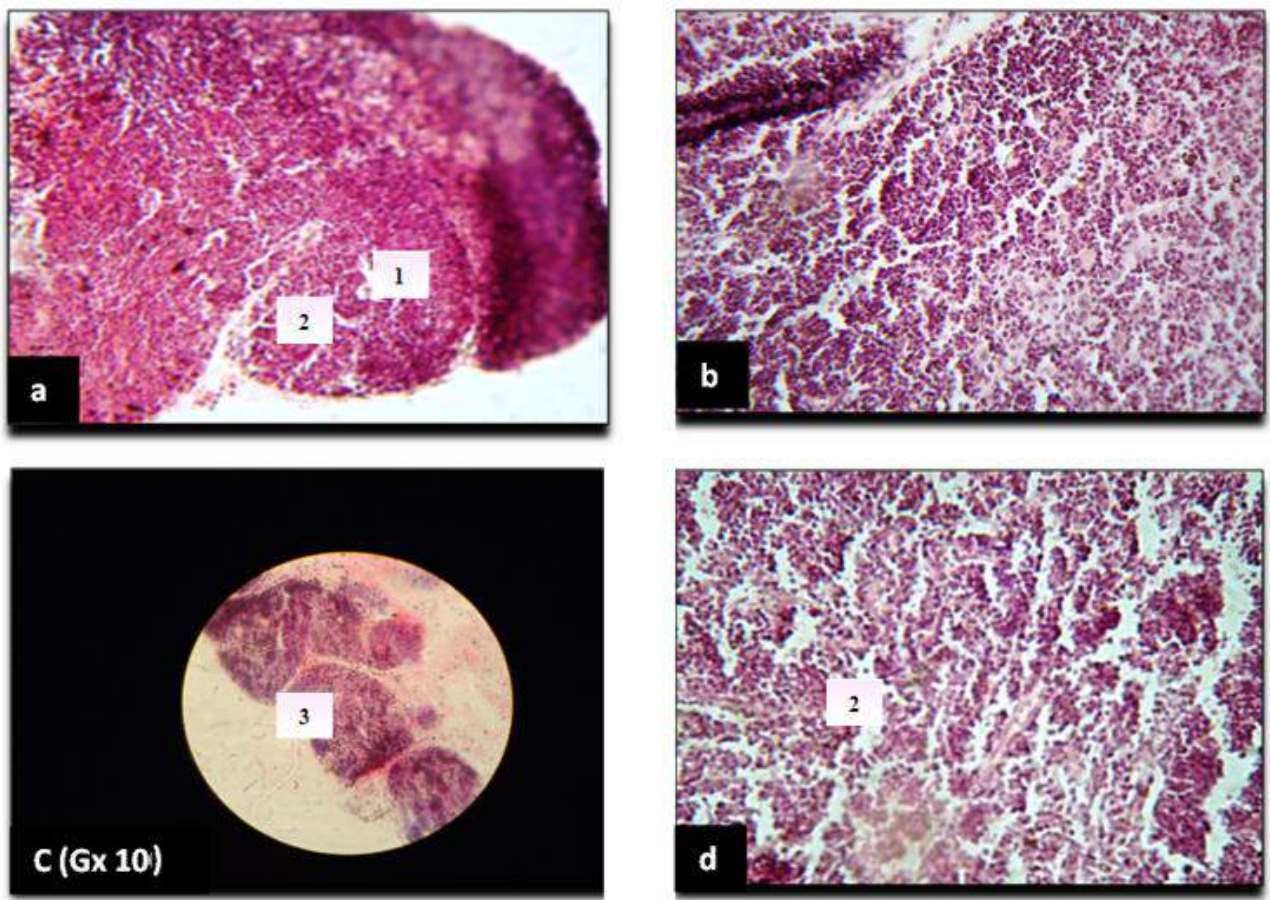

Figure 8: Histological sections of the thymus of female BALB/c mice (400X). a: control group, b: group of 0.5\% sweeteners, c: group of $1 \%$ sweeteners, d: group of $2 \%$ sweeteners. a1, b1: cortical zone; a2, b2: spinal zone; c3: thymic lobules.

\section{Lungs}

No histological disturbances including respiratory infections or pulmonary lymphomas were observed in all groups of both sexes. The epithelial cells of the groups having received the sweeteners have an ordinary shape, compared to those of the control group (Figure 9, 10).
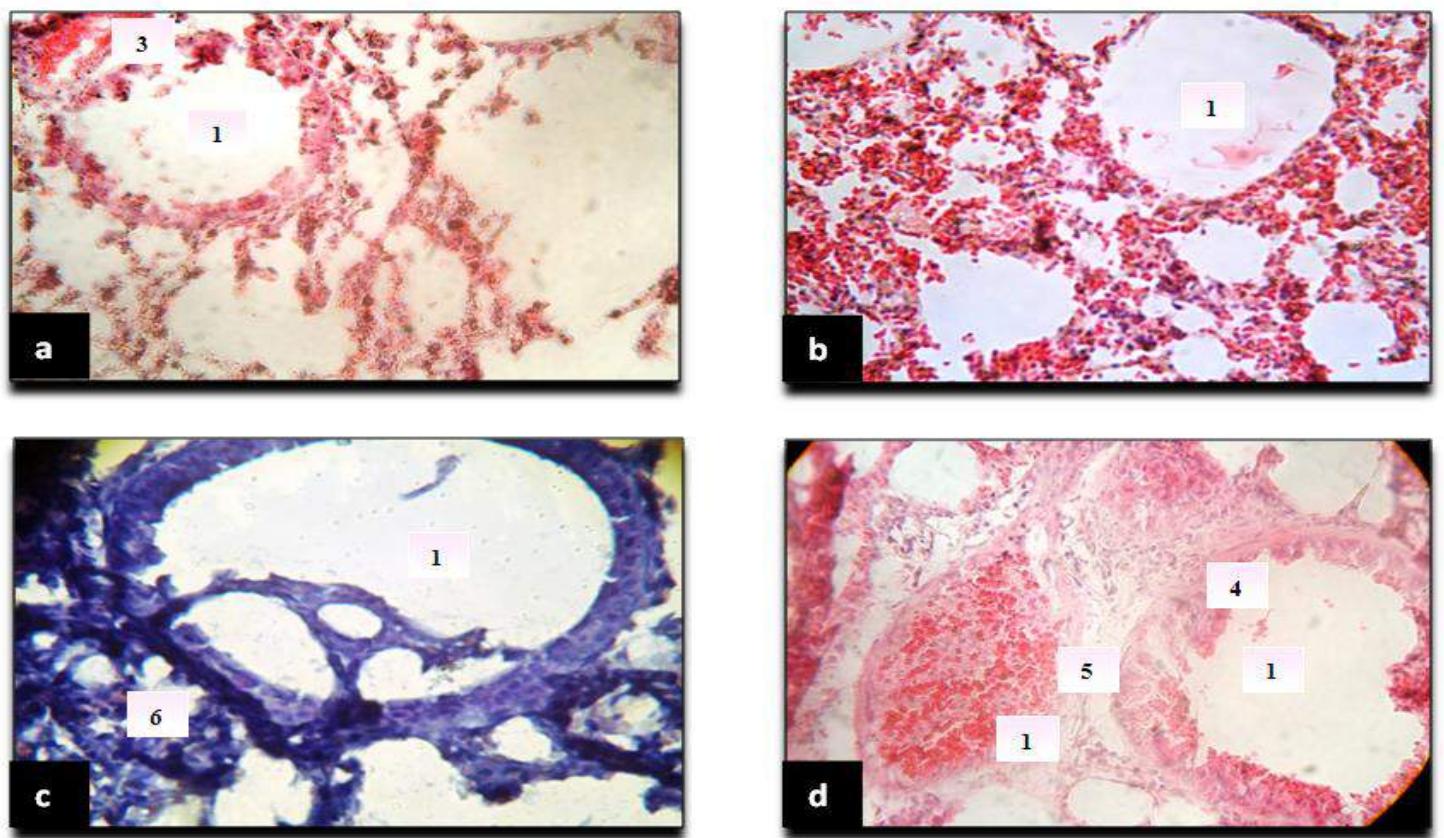

Figure 9: Histological sections of lungs of male BALB/c mice (400X). a: control group, b: group of 0.5\% sweeteners, c: group of $1 \%$ sweeteners, d: group of $2 \%$ sweeteners. a1, b1, c1: bronchi; a2, b2: bronchioles; a3, b3, c3, d3: pulmonary artery; d4: bronchial wall; d5: cartilage nodules, c6: transitional or respiratory bronchioles. 

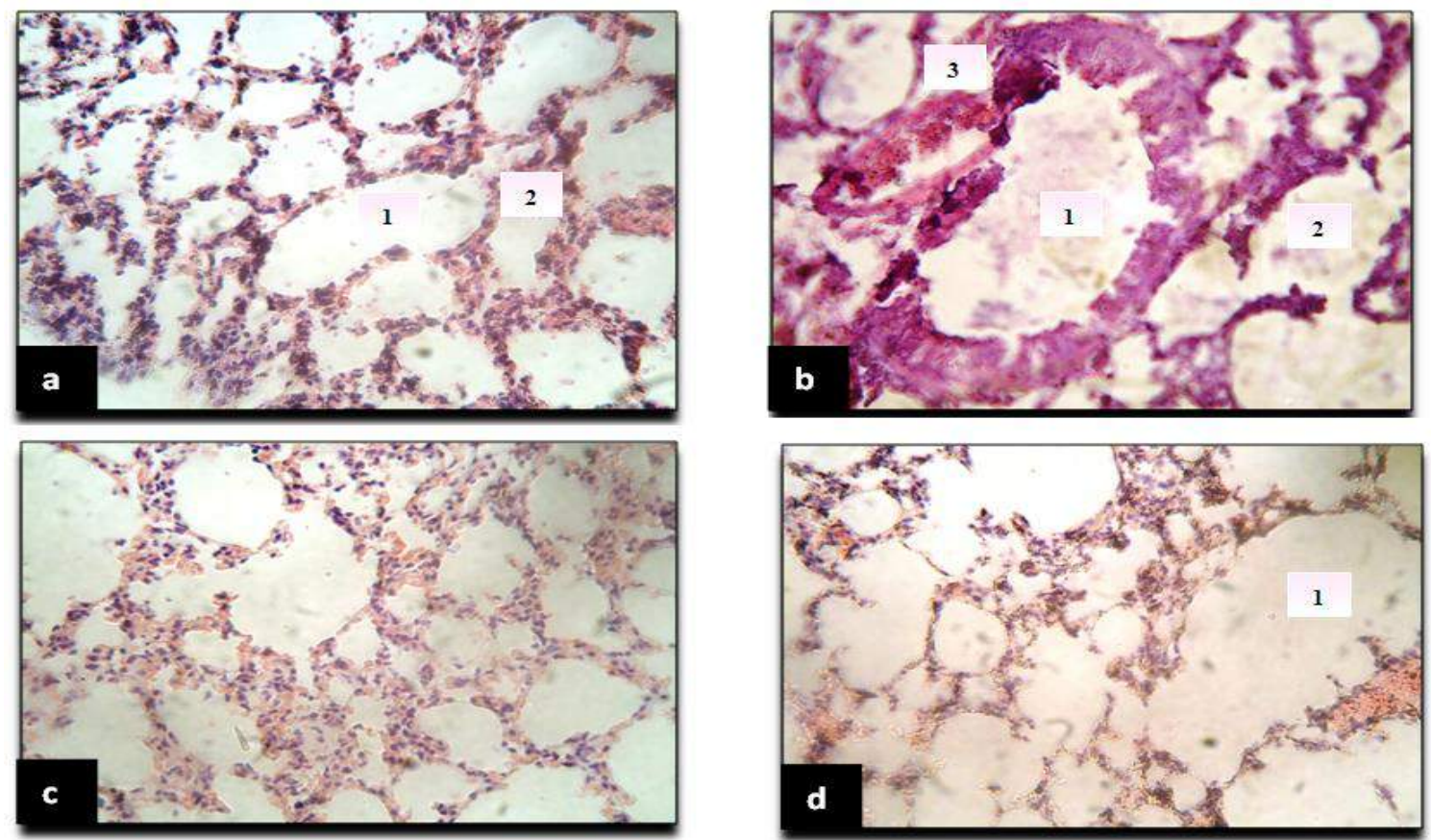

Figure 10: Histological sections of lungs of female BALB/c mice (400X). a: control group, b: group of 0.5\% sweeteners, c: group of $1 \%$ sweeteners, d: group of $2 \%$ sweeteners. a1, b1, c1: bronchi; a2, b2: bronchioles; a3, b3, c3, d3: pulmonary artery; d4: bronchial wall; d5: cartilage nodules, c6: transitional or respiratory bronchioles.

\section{Bladder}

Comparison between the control group and the other groups was showed a cell hyperplasia in groups consuming the sweeteners (figure 11,12).
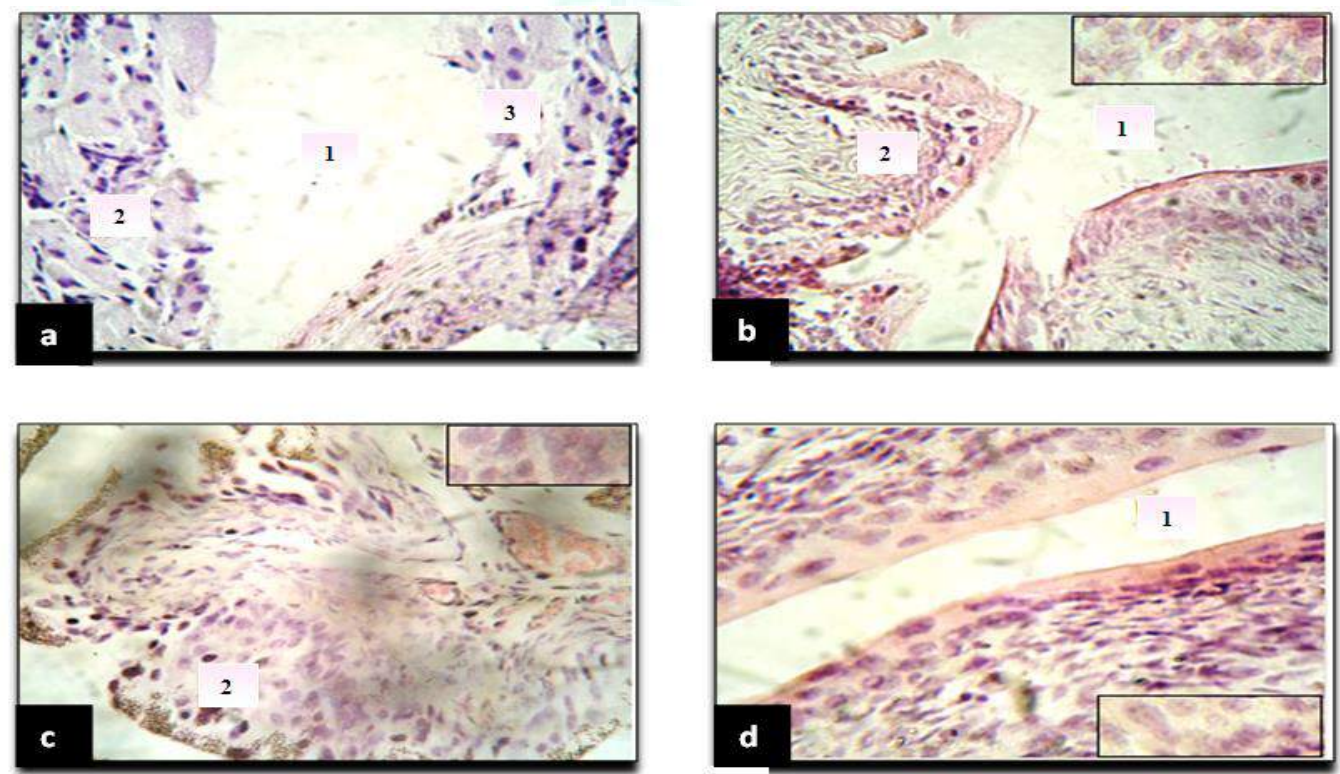

Figure 11: Histological sections of the bladder of male BALB/c mice (400X). a: control group, b: group of 0.5\% sweeteners, c: group of $1 \%$ sweeteners, d: group of $2 \%$ sweeteners. a1, b1, c1: bladder lumen; a2, b2, c2, d2: urinary epithelium; c3: racket cells. 

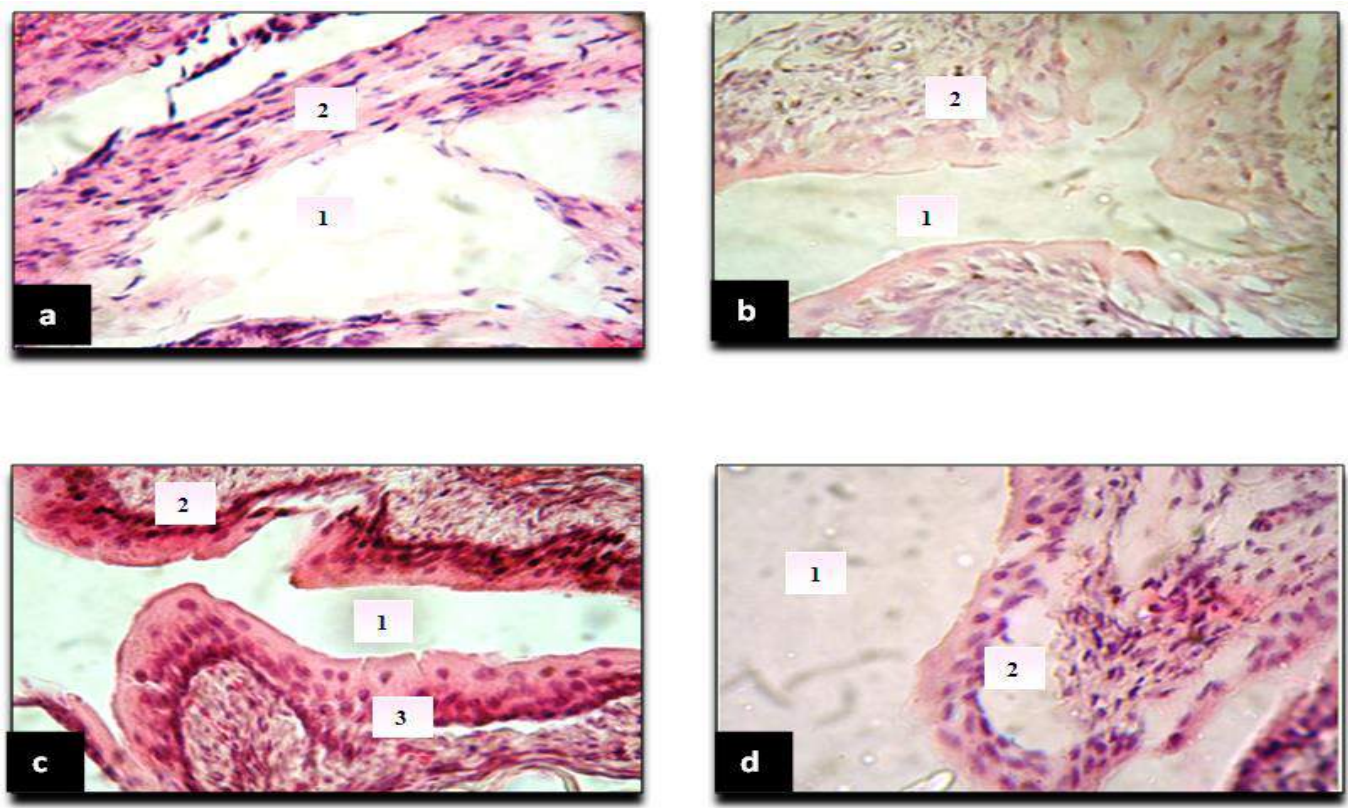

Figure 12: Histological sections of the bladder of females BALB/c mice (400X). a: control group, b: group of $0.5 \%$ sweeteners, c: group of $1 \%$ sweeteners, d: group of $2 \%$ sweeteners. a1, b1, c1: bladder lumen; a2, b2, c2, d2: urinary epithelium; c3: racket cells.

\section{Evaluation of immunoglobulins by reversed single radial immunodiffusion}

The results of the evolution of the mean square diameter $\left(d^{2}\right)$ are shown in figure 13. In BALB/c, females received a dose of $0.5 \%$ sweeteners, the $\left(\mathrm{d}^{2}\right)\left(\mathrm{mm}^{2}\right)\left(2.33 \pm 0.61 \mathrm{~mm}^{2}\right)$ is lower than the control group $\left(2.5 \pm 0.88 \mathrm{~mm}^{2}\right)$ while the $\left(\mathrm{d}^{2}\right)$ of the mice receiving doses of $1 \%\left(2.75 \pm 0.86 \mathrm{~mm}^{2}\right)$ is greater than that of the control group. The same result was noticed in the mice receiving the $2 \%$ dose $\left(3.66 \pm 0.66 \mathrm{~mm}^{2}\right)$. The results in males showed $\left(\mathrm{d}^{2}\right)$ very close. The $\mathrm{d}^{2}$ of the mice receiving the dose of $0.5 \%\left(1.25 \pm 0.35 \mathrm{~mm}^{2}\right)$ is lower than that of the control group $\left(1.5 \pm 0.34 \mathrm{~mm}^{2}\right)$. The mice receiving $2 \%$ of sweeteners have a $\mathrm{d}^{2}$ identical to that of the control group $\left(1.5 \pm 0.5 \mathrm{~mm}^{2}\right)$. On the other hand, the $\mathrm{d}^{2}$ of the animals of the third group (1.83 $\left.\pm 0.40 \mathrm{~mm}^{2}\right)$ is higher than that of the control group. The statistical analysis does not detect any significant difference between the diameters of the control group and the other groups $(\mathrm{p}>0.05)$.

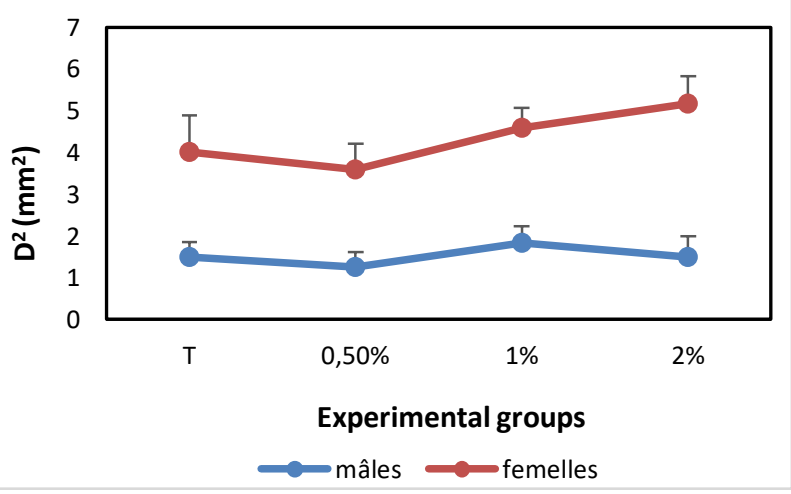

Figure 13: Comparison of the square diameters of the Ac-Ag precipitate of the mice subjected to the experiment. Data is expressed as the mean \pm standard error of the mean of two replicates $(n=6)$. D2: square diameter, grT: group receives drinking water with $0 \%$ sweeteners (control group). gr0,5\%: group receives $0,5 \%$ of sweeteners in drinking water. gr $1 \%$ : group receives $1 \%$ of sweeteners in drinking water. gr $2 \%$ : group receives $2 \%$ in drinking water.

\section{DISCUSSION}

Our experimental study has considered some parameters of immunomodulation of two sweeteners (sodium saccharin and potassium acesulfame) in mice BALB/c. In both sexes, the results obtained reveal a significant difference in the consumed water. This is due to its content sweeteners that impact on consumption because of their sweet taste. Also, we noticed gaining weight in all groups consuming sweeteners, but the statistical analysis does not confirm it for both sexes. The study of Kennedy et al., 197628 showed that male and female dogs fed with low doses of saccharin have a low weight gain during the experimental period. According to a study of Swithers et al., 2009, the use of sweeteners such as aspartame and saccharin in yogurt promotes weight gain in the rat. They also observed that the rats receiving sweet yogurt with saccharin tended to eat more and longer and consequently stored more fat. According to these researches, the sweet sensation adapts the body to highly caloric intake that does not materializing, the animals eat more and longer to reach satiety 29 . Evaluation of organ weights reveals that sweeteners have no effect on the weight of the four organs studied (spleen, thymus, lungs and bladder). These results confirm the work of Kennedy et al., 1976, which showed that body weights (liver, kidneys, spleen, gonads, heart, brain, adrenal gland and thyroid gland) of two sexes of dogs are not different than those of control animals ${ }^{28}$. The histological study reveals no abnormalities of the thymus and lungs while significant disturbances are observed on the spleen of the mice at the $2 \%$ dose and on the bladder of the groups receiving the $1 \%$ and $2 \%$ doses. Epidemiological studies carried out by Auerbach and Garfinkel, 1989 on histological changes of the bladder during the use of artificial sweeteners have shown that there is no relationship between the histological changes of the bladder and the use of artificial sweeteners. This study concluded that the risk of bladder cancer requires a long time to be established ${ }^{30}$. In our case, the animals show no change in immunoglobulin levels. Mantovani et al., 1980 studies the effect of saccharin on cellmediated immune response mechanisms, and have shown that a dose of 0.1 to $5 \mathrm{mg} / \mathrm{ml}$ induces cytolytic activity of CD- 
COBS peritoneal macrophages 12 . A direct cytotoxic effect is observed at a concentration of $2 \mathrm{mg} / \mathrm{ml}$. The blastogenic response of doses ranging from 0.2 to $0.5 \mathrm{mg} / \mathrm{ml}$ of saccharin shows an inhibition of mitogenic activity whereas doses of $0.05-0.2 \mathrm{mg} / \mathrm{ml}$ cause suppression of blastogenic activity. A marked inhibition of the immune response is also observed at doses of $2 \mathrm{mg} / \mathrm{ml}$ but this time in BALB/c mice. The Mantovani study concluded that saccha¥rin concentrations affecting rat lymphoid cells fed with $5 \%$ of saccharin (a dose inducing bladder cancer in rats), this compound could be present in sufficient quantities in the bladder to suppress the defense mechanisms provided by lymphoid cells 12. According to Luini et al. (1981), the production of IgG, after the first immunization, knows a suppression of the primary immune response by the use of doses of saccharine ranging from 1 to $5 \%$ leading to a decrease in the number of splenocytes during the experimentation ${ }^{13}$. In 2013, a study on the effect of natural and artificial sweeteners on the immune system found that they are not cytotoxic; however, they do have an impact on certain cellular pathways. All artificial sweeteners containing aspartame, saccharin and sucralose appear to inhibit inflammatory activity in vitro. They may potentially reduce humoral immunity thus increasing susceptibility of host defense against extracellular pathogens ${ }^{14}$.

\section{CONCLUSION}

This work has allowed evaluating experimentally some immunotoxic effects of the subchronic consumption of two sweeteners: sodium saccharin and potassium acesulfame at doses of $0,0.5,1$ and $2 \%$ in drinking water in BALB/c mice. The study focuses on the weight change, the relative weight of certain organs and their histology, as well as the determination of immunoglobulins by reversed single radial immunodiffusion. The results show a significant increase in the consumption of sweeteners in groups receiving doses of $1 \%(147,69 \pm 0.57 \mathrm{ml})$ and $2 \%(154,44 \pm 0.49 \mathrm{ml})$ compared with the control group $(132.06 \pm 0.45 \mathrm{ml})(\mathrm{p}<0.05)$. On the other hand, no significant difference was found between the average weight of the groups consuming the sweeteners and the control mice, regardless of the dose of ingested sweeteners $(p>0.05)$. Histological examination reveals no tissue abnormalities of the thymus and lungs in treated groups, but the follicular cells of the spleen in the group receiving $2 \%$ of sweeteners appear voluminous and atypical. Cellular hyperplasia was observed in the mice who received doses of $1 \%$ and $2 \%$. Furthermore, the results of the immunochemical technique did not show any variation in the level of immunoglobulins directed against casein in the groups consuming the sweeteners compared to the control group ( $\mathrm{p}>0.05)$.

All these results allow concluding that an excess of sweeteners has harmful effects on the immune system in general and on the secondary immune response in particular. Excessive consumption of sweeteners may cause histological abnormalities in the spleen and bladder in mice.

\section{Conflict of interest}

The authors declare no conflicts of interest.

\section{REFERENCES}

[1] Moll M, Moll N. Précis des Risques Alimentaires. Lavoisier Tec et Doc : Paris, France ; 2000.

[2] Pearson RL. Saccharin, Low-Calorie Sweeteners. In Alternatives Sweeteners, $3^{\text {rd }}$ ed. Nabors LO, Eds. Boca Raton: CRC Press; 2001. P. 147-165.

[3] Klug C, von Rymon Lipinski GW. Acesulfame K. In Sweeteners and Sugar Alternatives in Food Technology; O'Donnell K, Kearsley MW. Eds. Oxford: John Wiley \& Sons; 2012. P. 93-112.
[4] Journal officiel $n^{\circ} 94$. Conditions d'Utilisation des Edulcorants dans les Denrées Alimentaires; Article 5, The General Secretariat of the Government: Algiers, 1999 http://www.douane.gov.dz/pdf/diverses\%20reglementations/ Arret\%C3\%A915\%2012\%201999.pdf (accessed December, 15, 1999).

[5] Taylor JM, Weinberger MA, Friedman L. Chronic Toxicity and Carcinogenicity to the Urinary Bladder of Sodium Saccharin in the in Utero-exposed Rat, Toxicology and Applied Pharmacology, 1980; 54(1):57-75.

[6] Arnold, D. L. Two Generation Saccharin Bioassays, Environmental Health Perspectives, 1983; 50:27-36.

[7] Ellwein LB, Cohen SM. The Health Risks of Saccharin Revisited, Critical Reviews in Toxicology, 1990; 20(5):311-326.

[8] Zurlo J, Squire RA. Is Saccharin Safe? Animal Testing Revisited, Journal of the National Cancer Institute, 1998; 90(1):2-3.

[9] Whitehouse C R, Boullata J, McCauley LA. The Potential Toxicity of Artificial Sweeteners, Workplace Health \& Safety, 2008: 56(6):251-261.

[10] Mukherjee A, Chakrabarti J. In Vivo Cytogenetic Studies on Mice Exposed to Acesulfame-K-a Non-Nutritive Sweetener, Food and Chemical Toxicology, 1997; 35(12):1177-1179.

[11] Weihrauch MR, Diehl V. Artificial Sweeteners: Do They Bear a Carcinogenic Risk? Annals of Oncology, 2004; 15(10):14601465.

[12] Mantovani A, Luini W, Candiani GP, Salmona M, Spreafico F, Garattini S. In Vitro Effects of Saccharin on Cell-Mediated Host Defense Mechanisms, Toxicology Letters, 1980; 5(3):287-295.

[13] Luini W, Mantovani A, Garattini S. Effects of Saccharin on Primary Humoral Antibody Production in Rats, Toxicology Letters, 1981; 8(1):1-6.

[14] Rahiman F, Pool EJ. The in Vitro Effects of Artificial and Natural Sweeteners on the Immune System Using Whole Blood Culture Assays. Journal of Immunoassay and Immunochemistry, 2014; 35(1):26-36

[15] Cohen SM, Ellwein LB, Okamura T, Masui T, Johansson SL, Smith RA, Wehner JM, Khachab M, Chappel CI, Schoenig GP, Emerson JL, Garland EM. Comparative Bladder Tumor Promoting Activity of Sodium Saccharin, Sodium Ascorbate, Related Acids, and Calcium Salts in Rats, Cancer Research, 1991; 51(7):1766-1777.

[16] Baile CJ, Day C, Knapper, JM, Turner SL, Flatt PR. Antihyperglycaemic Effect of Saccharin in Diabetic Ob/Ob Mice, British Journal of Pharmacology and Chemotherapy, 1996; 120(1):74.

[17] Baldridge JR, Lacy MJ. Adjuvants. In Basic Methods in Antibody Production and Characterization. Howard GC, Bethell DR, Eds. Boca Raton: CRC Press; 2000. P. 19-29.

[18] Green JA, Manson MM. Production of Polyclonal Antisera. In Immunochemical Protocols. Pound JD, Eds. Totowa: Humana Press; 1998. P. 01-04.

[19] Page M, Thorpe R. Immunogen Preparation and Immunization Procedures for Rats and Mice. In The Protein Protocols Handbook. Walker J M. Eds. Totowa: Humana Press; 2002. P. 1109-1110.

[20] Burns R. Immunization Strategies for Antibody Production. In Immunochemical protocols. Burns R. Eds. Totowa: Humana Press; 2005. P. 01-11.

[21] Parasuraman S, Raveendran R, Kesavan R. Blood Sample Collection in Small Laboratory Animals, Journal of Pharmacology \& Pharmacotherapeutics, 2010; 1(2):87-93.

[22] Wolfensohn S, Lloyd M. Humane Methods of Killing. In Handbook of Laboratory Animal Management and Welfare. Wolfensohn S, Lloyd M. Eds. Oxford: John Wiley \& Sons; 2008. P. 74-84.

[23] Bensalem M. Techniques Histologiques: Théorie et Pratique. Eds. Algiers: Office des Publications Universitaires; 1998. P. 622.

[24] Smith PJ, Warfield JL. Specimen Handling and Preparation for Routine Diagnostic Histopathology. In The Science of Laboratory Diagnosis. Crocker J, Burnett D. Eds. Oxford: John Wiley \& Sons; 2005. P. 3-15.

[25] Vaerman JP, Lebacq-Verheyden AM, Scolari L, Heramans JF. Further Studies on Single Radial Immunodiffusion-I: Direct Propportionality between Area of Precipitate and Reciprocal of Antibody Concentration, Immunochemistry, 1969; 6(2):279285.

[26] Vaerman JP, Lebacq-Verhayden AM, Scolari L, Heremans JF. Further Studies on Single Radial Immunodiffusion-II the 
Reversed System: Diffusion of Antibodies in Antigen-Containing Gels, Immunochemistry, 1969; 6(2):287-293.

[27] Bailey GS. Single Radial Immunodiffusion. In The Protein Protocols Handbook. Walker JM. Eds. Totowa: Humana Press; 1996. P. 753-755.

[28] Kennedy GL, Fancher OE, Calandra JC. Subacute Toxicity Studies with Sodium Saccharin and two Hydrolytic Derivatives, Toxicology, 1976; 6(2):133-138.
[29] Swithers, S. E.; Baker, C. R.; Davidson, T. L. General and Persistent Effects of High-Intensity Sweeteners on Body Weight Gain and Caloric Compensation in Rats, Behavioral Neuroscience, 2009; 123(4):772-780.

[30] Auerbach 0, Garfinkel L. Histologic Changes in the Urinary Bladder in Relation to Cigarette Smoking and Use of Artificial Sweeteners, Cancer, 1989; 64(5):983-987. 